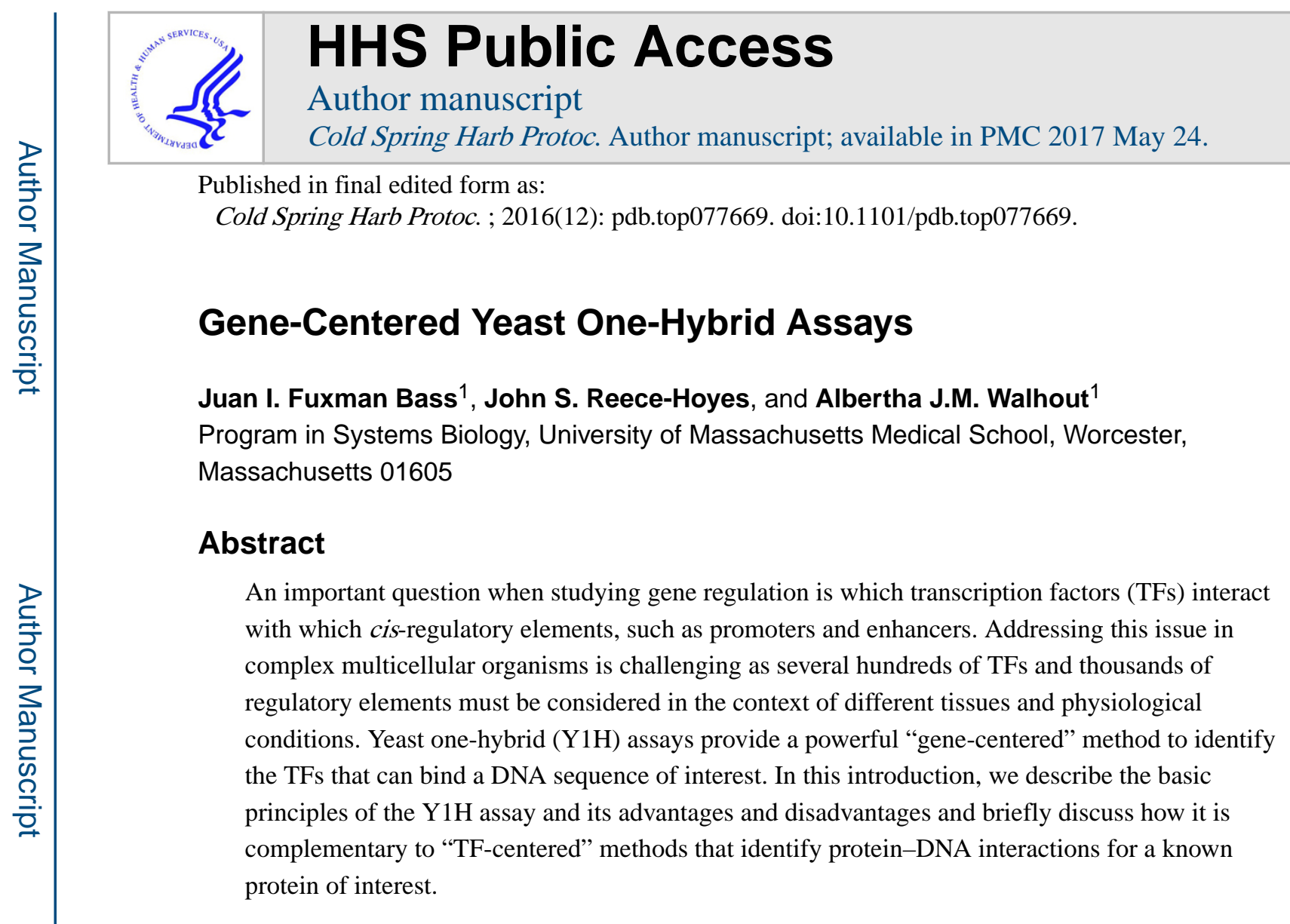

\title{
INTRODUCTION
}

Precise spatiotemporal gene expression plays a central role in development, homeostasis, and response to environmental cues. Gene expression is largely controlled by the specific binding of transcription factors (TFs) to DNA regulatory regions such as promoters and enhancers. TFs comprise $5 \%-10 \%$ of the protein-coding genes of most organisms (ReeceHoyes et al. 2005; Kummerfeld and Teichmann 2006; Vaquerizas et al. 2009). Interactions between TFs and regulatory DNA sequences can be experimentally identified using approaches that are either "TF-centered," which identify the DNA targets of a protein of interest, or "gene-centered," which identify the repertoire of TFs that bind a DNA sequence of interest (Walhout 2006; Arda and Walhout 2009). TF-centered approaches include chromatin immunoprecipitation (ChIP) (Ren et al. 2000) and protein-binding microarrays (Berger et al. 2006), whereas the yeast one-hybrid (Y1H) assay (Deplancke et al. 2004) is a gene-centered approach.

\section{PRINCIPLES OF Y1H ASSAYS}

Y1H assays involve two main components (Fig. 1): first, a reporter construct in which a DNA fragment of interest (the DNA "bait") is cloned upstream of a reporter gene(s), and, second, a plasmid that expresses a "prey" hybrid protein (hence the one-hybrid name) comprising a TF of interest fused to the activation domain (AD) of the yeast TF Gal4. Both components are introduced into a budding yeast strain, and the bait is used to "fish" for

\footnotetext{
${ }^{1}$ Correspondence: juan.fuxmanbass@ umassmed.edu; marian.walhout@umassmed.edu.
} 
interacting preys: If the hybrid TF binds to the DNA of interest, the AD will induce the expression of the reporter gene(s). Interactions involving both TF activators and repressors are detectable by this assay, as the activation of reporter expression is driven by the yeast AD. However, to distinguish between activators and repressors, functional assays should be performed in an endogenous system using nonhybrid TFs.

The Y1H system can be used to identify protein-DNA interactions (PDIs) with short cisregulatory elements (as single copy or tandem repeats) (Li and Herskowitz 1993; Deplancke et al. 2006; Reece-Hoyes et al. 2009) as well as with longer and more complex DNA fragments such as promoters or enhancers (Martinez et al. 2008; Arda et al. 2010; ReeceHoyes et al. 2011a; Fuxman Bass et al. 2014, 2015e). Cloning of the DNA baits to generate reporter constructs can be achieved by traditional restriction enzyme cloning or by recombination-based technologies such as Gateway cloning (Walhout et al. 2000b).

Multiple reporters have been used to detect interactions in $\mathrm{Y} 1 \mathrm{H}$ assays, including auxotrophic genes, such as $H I S 3, U R A 3, T R P 1$, and $L E U 2$, that enable growth in the absence of histidine, uracil, tryptophan, and leucine, respectively, and $L a c Z$, which encodes for the bacterial enzyme $\beta$-galactosidase, which is detectable in colorimetric assays. The Y1H protocol that we have developed employs two reporter genes, HIS3 and LacZ, integrated into the yeast genome at two different loci (Deplancke et al. 2004). Integration ensures that every yeast cell has the same number of reporter constructs, thus eliminating confusion between yeast that are positive in the assay because of a PDI and those that appear positive owing to basal expression in colonies harboring higher copy numbers of the reporter plasmids. Furthermore, for an interaction to be detected, it needs to induce reporter expression from two separate loci in the same yeast nucleus-thus the interaction is tested twice, which provides an inherent retest. Activation of the HIS 3 reporter results in yeast growth in the absence of histidine and in the presence of enough 3-aminotriazole (3AT), a competitive inhibitor of the Hisp3 enzyme, to inhibit growth driven by background HIS3 expression. Activation of the $L a c Z$ reporter results in higher levels of $\beta$-galactosidase expression, which is monitored using a colorimetric assay in which colorless $\mathrm{X}$-gal is modified into a blue compound.

An important aspect of undertaking $\mathrm{Y} 1 \mathrm{H}$ assays is the selection of prey source to be screened. The most widely used source of prey molecules is a cDNA library generated by extracting mRNA from a tissue/organism of interest and cloning the reverse-transcribed products into a vector backbone that encodes an adjacent AD moiety (Walhout et al. 2000a,b). Such libraries are commercially available, can be requested from other academic laboratories, or can be generated in house. However, $\mathrm{Y} 1 \mathrm{H}$ assays that screen cDNA libraries suffer from two drawbacks: first, it is challenging to know whether all TFs are present in the library and, second, TFs are generally expressed at low levels and therefore are relatively uncommon in any cDNA library (especially nonnormalized ones). The latter drawback can be somewhat overcome by screening large numbers of colonies to ensure that even uncommon transcripts are interrogated. However, the former can only be overcome by screening a different prey source comprising a characterized set of TF clones, such as those available from Gateway-compatible collections of cloned open reading frames

("ORFeomes") (Reboul et al. 2003; Rual et al. 2004). These TF clones can be combined and 
screened as a "TF minilibrary" (Deplancke et al. 2004), but a more efficient technique is to screen these clones individually as an array to ensure that every TF is interrogated and to remove the need to sequence the clones from the positive yeast because the TF identity at each array position is known (Vermeirssen et al. 2007). Recently, high-throughput $\mathrm{Y} 1 \mathrm{H}$ platforms have been developed for four widely studied organisms (Caenorhabditis elegans, Drosophila melanogaster, Arabidopsis thaliana, and human) (Gaudinier et al. 2011; Hens et al. 2011; Reece-Hoyes et al. 2011a,b). These platforms use robotics to manipulate AD-TF arrays in a 1536-colony format. This greatly increases throughput and sensitivity and allows testing all bait-prey combinations four times, providing independent technical replicates that reduce both false-positive and false-negative rates.

In associated protocols, we present detailed methods for conducting gene-centered $\mathrm{Y} 1 \mathrm{H}$ assays. First, we outline how to produce bait strains and conduct high-efficiency transformations (see Protocol: Generating Bait Strains for Yeast One-Hybrid Assays [Fuxman Bass et al. 2015a]). Next, we detail how to perform a TF screen by transforming the yeast bait strain with an AD-prey library (see Protocol: Performing Yeast One-Hybrid Library Screens [Fuxman Bass et al. 2015b]). Finally, various steps in these procedures require the last two protocols that we present (Protocol: Colony Lift Colorimetric Assay for $\beta$-Galactosidase Activity [Fuxman Bass et al. 2015c] and Protocol: Zymolase Treatment and Polymerase Chain Reaction Amplification from Genomic and Plasmid Templates from Yeast [Fuxman Bass et al. 2015d]).

\section{ADVANTAGES AND DISADVANTAGES OF Y1H ASSAYS}

The fact that $\mathrm{Y} 1 \mathrm{H}$ assays detect PDIs in the milieu of the yeast nucleus rather than in their endogenous biological context provides both advantages and disadvantages (Table 1). As with any methodology, $\mathrm{Y} 1 \mathrm{H}$ assays are subject to false-negative and false-positive interactions. There are several explanations for missed PDIs: (1) Not every clone is transformed into yeast and gets the chance to be detected (this is most relevant when using libraries as a TF prey source); (2) the TF is absent from the clone source; (3) the TF might only bind to DNA as a heterodimer (and the current $\mathrm{Y} 1 \mathrm{H}$ system expresses only one TF at a time); (4) to bind DNA, the TF needs posttranslational modification(s) not available in yeast; and (5) the TF hybrid protein does not fold correctly in yeast. Regarding false positives, there are two different types to be considered. Technical false positives are interactions that cannot be reproduced when repeating the assay and can be filtered out by testing any detected PDI (at least) one more time. Biological false positives are interactions that can be robustly detected in yeast but never occur in vivo. It is challenging to determine whether an interaction is clearly a biological false positive because assays used to validate the interactions in vivo have their own false-negative rate (Walhout 2011). For instance, the effect of knocking down or knocking out a TF can be masked by functionally redundant interactions.

Perhaps the most important advantage of $\mathrm{Y} 1 \mathrm{H}$ is that it can determine which TFs from a collection of many hundreds bind and (potentially) regulate a gene of interest. This would be very challenging to achieve through TF-centered approaches, as this would require assaying all TFs individually. Furthermore, PDIs that are rare in vivo (because they occur for only a 
limited time, in only a few cells, or under a rare environmental condition) are difficult to detect directly from tissue. In Y1H assays, all the TFs are expressed in yeast from the same promoter, and so the ability of the assay to detect a PDI is independent of the in vivo conditions required for the interaction.

Ultimately, the comprehensive detection of the PDIs that drive gene regulation will require a combination of complementary approaches, such as ChIP, functional assays with reporter genes in the endogenous system, and genome editing of the TF binding sites followed by measures of target gene expression.

\section{Acknowledgments}

This work was supported by the National Institutes of Health grants DK068429 and GM082971 to A.J.M.W. J.I.F.B. was partially supported by a postdoctoral fellowship from the Pew Latin American Fellows Program.

\section{References}

Arda HE, Walhout AJM. Gene-centered regulatory networks. Brief Funct Genomics. 2009; doi: 10.1093/elp049

Arda HE, Taubert S, Conine C, Tsuda B, Van Gilst MR, Sequerra R, Doucette-Stam L, Yamamoto KR, Walhout AJM. Functional modularity of nuclear hormone receptors in a $C$. elegans gene regulatory network. Mol Syst Biol. 2010; 6:367. [PubMed: 20461074]

Berger MF, Philippakis AA, Qureshi AM, He FS, Estep PW 3rd, Bulyk ML. Compact, universal DNA microarrays to comprehensively determine transcription-factor binding site specificities. Nat Biotechnol. 2006; 24:1429-1435. [PubMed: 16998473]

Deplancke B, Dupuy D, Vidal M, Walhout AJM. A Gateway-compatible yeast one-hybrid system. Genome Res. 2004; 14:2093-2101. [PubMed: 15489331]

Deplancke B, Mukhopadhyay A, Ao W, Elewa AM, Grove CA, Martinez NJ, Sequerra R, DoucetteStam L, Reece-Hoyes JS, Hope IA, et al. A gene-centered $C$. elegans protein-DNA interaction network. Cell. 2006; 125:1193-1205. [PubMed: 16777607]

Fuxman Bass JI, Reece-Hoyes JS, Walhout AJM. Generating bait strains for yeast one-hybrid assays. Cold Spring Harb Protoc. 2015a; doi: 10.1101/pdb.prot088948

Fuxman Bass JI, Reece-Hoyes JS, Walhout AJM. Performing yeast one-hybrid library screens. Cold Spring Harb Protoc. 2015b; doi: 10.1101/pdb.prot088955

Fuxman Bass JI, Reece-Hoyes JS, Walhout AJM. Colony lift colorimetric assay for $\beta$-galactosidase activity. Cold Spring Harb Protoc. 2015c; doi: 10.1101/pdb.prot088963

Fuxman Bass JI, Reece-Hoyes JS, Walhout AJM. Zymolase treatment and polymerase chain reaction amplification from genomic and plasmid templates from yeast. Cold Spring Harb Protoc. 2015d; doi: 10.110/pdb.prot088971

Fuxman Bass JI, Sahni N, Shrestha S, Garcia-Gonzalez A, Mori A, Bhat N, Yi S, Hill DE, Vidal M, Walhout AJ. Human gene-centered transcription factor networks for enhancers and disease variants. Cell. 2015e; 161:661-673. [PubMed: 25910213]

Fuxman Bass JI, Tamburino AM, Mori A, Beittel N, Weirauch MT, Reece-Hoyes JS, Walhout AJ. Transcription factor binding to Caenorhabditis elegans first introns reveals lack of redundancy with gene promoters. Nucleic Acids Res. 2014; 42:153-162. [PubMed: 24068555]

Gaudinier A, Zhang L, Reece-Hoyes JS, Taylor-Teeples M, Pu L, Liu Z, Breton G, Pruneda-Paz JL, Kim D, Kay SA, et al. Enhanced Y1H assays for Arabidopsis. Nat Methods. 2011; 8:1053-1055. [PubMed: 22037706]

Hens K, Feuz J-D, Iagovitina A, Massouras A, Bryois J, Callaerts P, Celniker S, Deplancke B. Automated protein-DNA interaction screening of Drosophila regulatory elements. Nat Methods. 2011; 8:1065-1070. [PubMed: 22037703] 
Kummerfeld SK, Teichmann SA. DBD: A transcription factor prediction database. Nucleic Acids Res. 2006; 34:D74-D81. [PubMed: 16381970]

Li JJ, Herskowitz I. Isolation of the ORC6, a component of the yeast origin recognition complex by a one-hybrid system. Science. 1993; 262:1870-1874. [PubMed: 8266075]

Martinez NJ, Ow MC, Barrasa MI, Hammell M, Sequerra R, Doucette-Stamm L, Roth FP, Ambros V, Walhout AJM. A C. elegans genome-scale microRNA network contains composite feedback motifs with high flux capacity. Genes Dev. 2008; 22:2535-2549. [PubMed: 18794350]

Reboul J, Vaglio P, Rual JF, Lamesch P, Martinez M, Armstrong CM, Li S, Jacotot L, Bertin N, Janky $\mathrm{R}$, et al. $C$. elegans ORFeome version 1.1: Experimental verification of the genome annotation and resource for proteome-scale protein expression. Nat Genet. 2003; 34:35-41. [PubMed: 12679813]

Reece-Hoyes JS, Deplancke B, Shingles J, Grove CA, Hope IA, Walhout AJM. A compendium of $C$. elegans regulatory transcription factors: A resource for mapping transcription regulatory networks. Genome Biol. 2005; 6:R110. [PubMed: 16420670]

Reece-Hoyes JS, Deplancke B, Barrasa MI, Hatzold J, Smit RB, Arda HE, Pope PA, Gaudet J, Conradt $\mathrm{B}$, Walhout AJ. The $C$. elegans Snail homolog CES-1 can activate gene expression in vivo and share targets with bHLH transcription factors. Nucleic Acids Res. 2009; 37:3689-3698. [PubMed: 19372275]

Reece-Hoyes JS, Barutcu AR, Patton McCord R, Jeong J, Jian L, MacWilliams A, Yang X, SalehiAshtiani K, Hill DE, Blackshaw S, et al. Yeast one-hybrid assays for high-throughput human gene regulatory network mapping. Nat Methods. 2011a; 8:1050-1052. [PubMed: 22037702]

Reece-Hoyes JS, Diallo A, Kent A, Shrestha S, Kadreppa S, Pesyna C, Lajoie B, Dekker J, Myers CL, Walhout AJM. Enhanced yeast one-hybrid $(\mathrm{eY} 1 \mathrm{H})$ assays for high-throughput gene-centered regulatory network mapping. Nat Methods. 2011b; 8:1059-1064. [PubMed: 22037705]

Ren B, Robert F, Wyrick JJ, Aparicio O, Jennings EG, Simon I, Zeitlinger J, Schreiber J, Hannett N, Kanin E, et al. Genome-wide location and function of DNA binding proteins. Science. 2000; 290:2306-2309. [PubMed: 11125145]

Rual J-F, Hirozane-Kishikawa T, Hao T, Bertin N, Li S, Dricot A, Li N, Rosenberg J, Lamesch P, Vidalain P-O, et al. Human ORFeome version 1.1: A platform for reverse proteomics. Genome Res. 2004; 14:2128-2135. [PubMed: 15489335]

Vaquerizas JM, Kummerfeld SK, Teichmann SA, Luscombe NM. A census of human transcription factors: Function, expression and evolution. Nat Rev Genet. 2009; 10:252-263. [PubMed: 19274049]

Vermeirssen V, Deplancke B, Barrasa MI, Reece-Hoyes JS, Arda HE, Grove CA, Martinez NJ, Sequerra R, Doucette-Stamm L, Brent M, et al. Matrix and Steiner-triple-system smart pooling assays for high-performance transcription regulatory network mapping. Nat Methods. 2007; 4:659-664. [PubMed: 17589517]

Walhout AJM. Unraveling transcription regulatory networks by protein-DNA and protein-protein interaction mapping. Genome Res. 2006; 16:1445-1454. [PubMed: 17053092]

Walhout AJM. What does biologically meaningful mean? A perspective on gene regulatory network validation. Genome Biol. 2011; 12:109. [PubMed: 21489330]

Walhout AJM, Sordella R, Lu X, Hartley JL, Temple GF, Brasch MA, Thierry-Mieg N, Vidal M. Protein interaction mapping in $C$. elegans using proteins involved in vulval development. Science. 2000a; 287:116-122. [PubMed: 10615043]

Walhout AJM, Temple GF, Brasch MA, Hartley JL, Lorson MA, van den Heuvel S, Vidal M. GATEWAY recombinational cloning: Application to the cloning of large numbers of open reading frames or ORFeomes. Methods Enzymol. 2000b; 328:575-592. [PubMed: 11075367] 
A
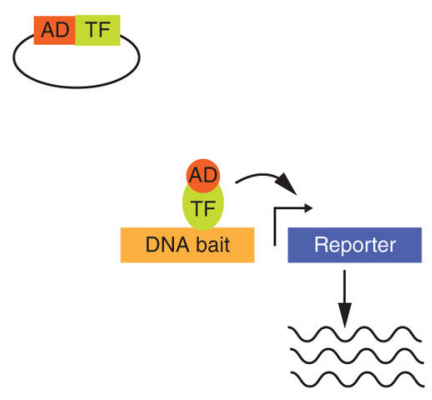

B

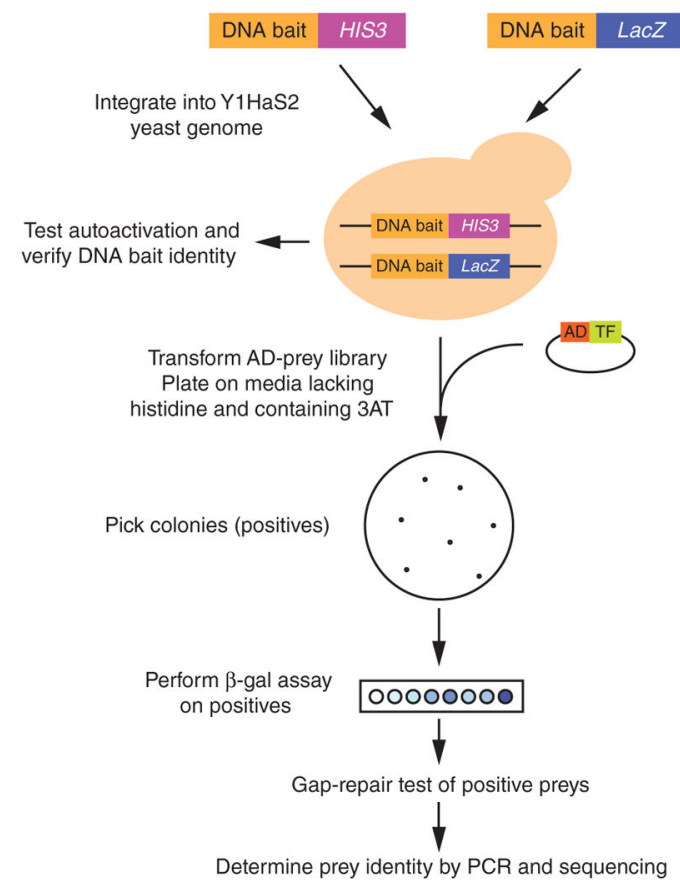

FIGURE 1.

The principles underlying the yeast one-hybrid technique and the pipeline for library screening. $(A)$ Yeast one-hybrid $(\mathrm{Y} 1 \mathrm{H})$ assays detect protein-DNA interactions between transcription factors (TFs) fused to the Gal4 activation domain (AD-TF "prey") and a DNA fragment of interest (DNA "bait"). The bait is cloned upstream of reporter genes, and each bait::reporter construct is integrated into the yeast genome. If the TF binds to the DNA of interest, the AD moiety will induce expression of the reporter. $(B)$ Outline of steps involved in generating a DNA bait yeast strain and performing an AD-cDNA library screen, as described in other protocols. The procedure involves integrating, by homologous recombination into a Y1HaS2 yeast strain, the two reporter cassettes with the bait sequence cloned upstream of both the HIS3 auxotrophic marker and the colorimetric LacZ marker. The screen is performed by transforming the yeast with an AD-prey library and selecting for growth on medium lacking histidine but containing 3-aminotriazole (3AT), a competitive inhibitor of the Hisp3 enzyme, followed by the colorimetric detection of $\beta$-galactosidase ( $\beta$ gal; leading to formation of a blue compound). Interactions are confirmed by conducting gap-repair tests, followed by polymerase chain reaction (PCR) and sequencing to identify the prey. 


\section{TABLE 1}

Advantages and disadvantages of the yeast one-hybrid technique

\begin{tabular}{ll}
\hline Advantages & Disadvantages \\
\hline $\begin{array}{l}\text { Identifies binding of multiple TFs with a DNA fragment of interest } \\
\begin{array}{l}\text { Condition-independent: can identify interactions with low- } \\
\text { abundance TFs that are difficult to detect directly from tissue }\end{array}\end{array}$ & Might identify PDIs that do not occur in vivo (biological false positives) \\
& Not (yet) adapted to detect PDIs involving heterodimers \\
\hline
\end{tabular}

TF, transcription factor; PDI, protein-DNA interaction. 